\title{
Altered patterns of cellular growth, morphology, replication and division in conditional-lethal mutants of the thermophilic archaeon Sulfolobus acidocaldarius
}

\author{
Rolf Bernander, ${ }^{1}$ Andrzej Poplawski ${ }^{1}$ and Dennis W. Grogan ${ }^{2}$
}

Author for correspondence: Rolf Bernander. Tel: +46 1847140 58. Fax: +4618 530396. e-mail: Rolf.Bernander@icm.uu.se

\footnotetext{
${ }^{1}$ Department of Cell and Molecular Biology, Box 596, Biomedical Center, Uppsala University, SE-751 24 Uppsala, Sweden

2 Department of Biological Sciences, PO Box 210006, University of Cincinnati, Cincinnati, OH 45221-0006, USA
}

\begin{abstract}
As a basis for studing the essential cellular processes of hyperthermophilic archaea, thermosensitive mutants of Sulfolobus acidocaldarius were isolated and characterized. Exponential-phase liquid cultures were shifted to the nonpermissive temperature and growth, viability, and distributions of cell mass and DNA content were measured as a function of time after the shift. The observed phenotypes demonstrate that chromosome replication, nucleoid organization, nucleoid partition and cell division, which normally are tightly co-ordinated during cellular growth, can be inhibited or uncoupled by mutation in this hyperthermophilic archaeon.
\end{abstract}

Keywords: Archaea, conditional mutants, flow cytometry, hyperthermophile, Sulfolobus

\section{INTRODUCTION}

Members of the domain Archaea comprise an evolutionary lineage of prokaryotes only distantly related to bacteria (Woese et al., 1990). Archaea from geo- and hydrothermal habitats include the most thermophilic organisms known (Stetter, 1999). They represent the deepest and shortest branches in the universal tree of life, and exhibit molecular features formerly thought to be uniquely eukaryotic. Therefore, studies of thermophilic archaea provide insights both into mechanisms of thermostability and into the fundamental evolutionary relationships among cellular organisms. Complete genome sequences show that thermophilic archaea employ homologues of both eukaryotic and prokaryotic genes for basic cellular functions (Bult et al., 1996; Kawarabayasi et al., 1998, 1999; Klenk et al., 1997; Smith et al., 1997). This functional mosaicism is also evident with respect to the cell cycle (Bernander, 1998), although the genes for a number of cell-cycle functions remain to be identified in archaea. This is consistent with the great evolutionary divergence of these prokaryotes from well characterized organisms, as well as their extreme physiological adaptations, and underscores the importance of investigating cellular processes in hyperthermophilic archaea by direct experimentation.

Abbreviations: DAPI, 4',6-diamidino-2-phenylindole; Ts, thermosensitive.
Members of the archaeal genus Sulfolobus grow optimally at about $80^{\circ} \mathrm{C}$ and $\mathrm{pH} 3$ under aerobic conditions. Sulfolobus spp. have emerged as important model systems for studies of hyperthermophilic archaea, including cell-cycle analyses (Bernander \& Poplawski, 1997; Hjort \& Bernander, 1999; Poplawski \& Bernander, 1997) and development of simple genetic techniques (Grogan, 1989, 1996; Grogan \& Gunsalus, 1993; Schleper et al., 1994). Here, we report the isolation and characterization of conditional-lethal mutants of Sulfolobus acidocaldarius. At the non-permissive temperature, initiation of chromosome replication, nucleoid organization and segregation, cellular growth, and cell division could be inhibited or uncoupled in these mutants, demonstrating their usefulness as tools for investigations of essential cellular processes of hyperthermophilic archaea.

\section{METHODS}

Strains and growth conditions. All thermosensitive (Ts) mutants were derived from Sulfolobus acidocaldarius strain DG64 (pyrB4; Grogan \& Gunsalus, 1993). Unless otherwise noted, liquid cultures were grown in a mineral medium (Grogan \& Gunsalus, 1993) supplemented with 2.0 g D-xylose $\mathrm{l}^{-1}, 1 \cdot 0 \mathrm{~g}$ acid-hydrolysed casein $\mathrm{l}^{-1}$ and $20 \mathrm{mg}$ uracil $\mathrm{l}^{-1}$. The permissive temperature used in the experiments was $70^{\circ} \mathrm{C}$ and the non-permissive temperature was $81^{\circ} \mathrm{C}$, unless otherwise noted. To select phenotypic revertants of Ts mutants, $1-5 \times 10^{8}$ cells grown at $70{ }^{\circ} \mathrm{C}$ were plated on medium 


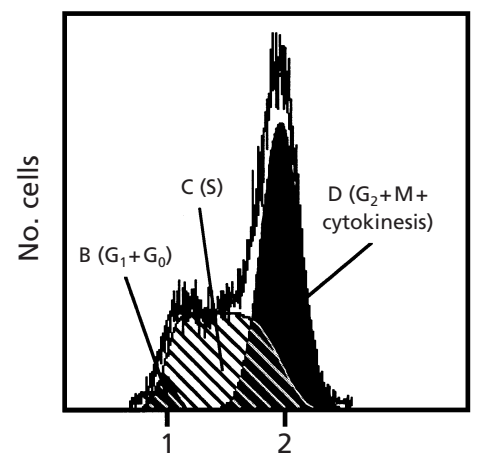

Genome equivalents (fluorescence)

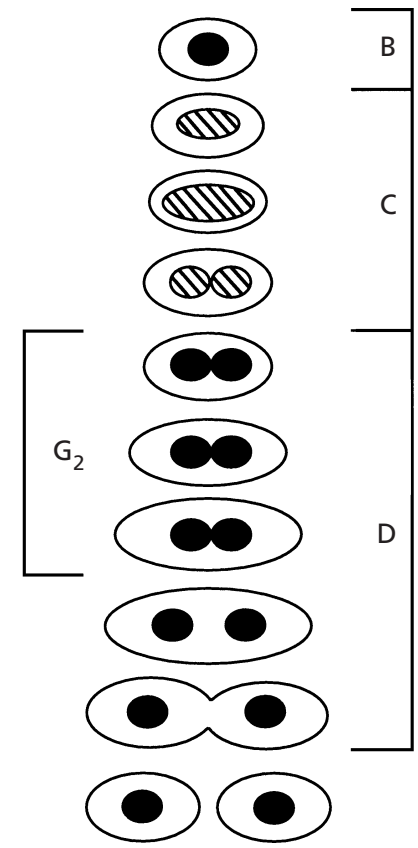

Fig. 1. DNA content distribution in an exponentially growing $S$. acidocaldarius culture and deduced relative lengths of the cell-cycle periods. A computer simulation that gave a good fit to the DNA content distribution generated by flow cytometry is shown within the graph (compare with Bernander \& Poplawski, 1997), and cells that were in different cell cycle periods at the time of sampling form overlapping distributions as indicated. The deduced cell cycle is shown to the right: note that the relative lengths of the different cell cycle periods are not drawn to scale. The presence of a $G_{2}$ period is based upon microscopy analyses (Poplawski \& Bernander, 1997). containing dextrin (Serva) in place of xylose, and incubated $7-10 \mathrm{~d}$ at $81^{\circ} \mathrm{C}$. Other growth media, plating methods and storage conditions have been described previously (Grogan \& Gunsalus, 1993; Grogan, 1995).

Mutant isolation. Cells of strain DG64 from late-exponential phase were suspended in $50 \mathrm{mM}$ potassium-MES buffer, $\mathrm{pH}$ $6 \cdot 0$, at a density of about $10^{9}$ cells $\mathrm{ml}^{-1}$ and treated with $100 \mu \mathrm{g}$ NTG ml ${ }^{-1}$ for $20 \mathrm{~min}$ at $37^{\circ} \mathrm{C}$. Typical survival rates under these conditions were $5-25 \%$. Colonies of survivors grown at $70{ }^{\circ} \mathrm{C}$ were replica plated at $70{ }^{\circ} \mathrm{C}$ and $83{ }^{\circ} \mathrm{C}$ (Grogan, 1995). Colonies failing to grow at the higher temperature were retested on solid medium to confirm Ts growth. Those scoring Ts were streaked for isolation, and tested for growth in liquid medium at $81^{\circ} \mathrm{C}$.

Temperature-shift experiments. Liquid cultures $(15 \mathrm{ml}$ in $100 \mathrm{ml}$ Erlenmeyer flasks) were grown with shaking at $70^{\circ} \mathrm{C}$ to stationary phase (about $2 \mathrm{~d}$ ). The cultures were then diluted by an appropriate factor (about $10^{3}$-fold in most cases) into $20 \mathrm{ml}$ fresh growth medium in new $100 \mathrm{ml}$ flasks, so that an optical density of $0 \cdot 02$ to $0 \cdot 1$ was reached after $2 \mathrm{~d}$ additional incubation. As a result, the mutant cultures had been growing undisturbed for up to 10 generations when the temperature shift was performed.

The cultures were sampled (zero time point) for flow cytometry and epifluorescence microscopy, shifted to $81^{\circ} \mathrm{C}$, and further sampled at different time points. Samples for flow cytometry were collected by pipetting aliquots from the cultures directly into ice-cold ethanol $(70 \%, \mathrm{v} / \mathrm{v}$, final concentration). The volume collected was adjusted to obtain approximately the same concentration of cells in each sample. For microscopy, the samples were concentrated by centrifugation before ethanol fixation.

Flow cytometry. Sampling, preparation and staining of cells, as well as flow cytometry, were performed as described previously (Bernander \& Poplawski, 1997). Between 2000 and 10000 cells were analysed in each sample and the data were plotted using the FCSPress software (Ray Hicks).
Phase-contrast and fluorescence microscopy. Combined phase-contrast and fluorescence microscopy was performed as described previously (Poplawski \& Bernander, 1997), except that a higher DAPI $\left(4^{\prime}, 6\right.$-diamidino-2-phenylindole) concentration was used $\left(0 \cdot 5-1 \mu \mathrm{g} \mathrm{ml}^{-1}\right)$. Figures were prepared using Adobe Photoshop software.

Growth curves. Culture growth and numbers of c.f.u. (viability) were monitored in a similar manner as for the flow cytometry and microscopy analyses, but on separate sets of cultures. Turbidity was measured as apparent $\mathrm{OD}_{600}$ in a Milton-Roy Spectronic 21D spectrophotometer, using samples diluted in growth medium as necessary to achieve an OD value of less than about $0 \cdot 3$. Viable titre was measured by plating serial 1:10 dilutions of duplicate culture aliquots at $70^{\circ} \mathrm{C}$.

\section{RESULTS}

\section{Isolation of Ts mutants}

Mutants with a Ts growth phenotype were isolated by replica plating of $S$. acidocaldarius colonies grown at $70{ }^{\circ} \mathrm{C}$ after mutagenesis, using a non-permissive plating temperature of $83^{\circ} \mathrm{C}$. Scoring of approximately 15000 colonies by this method yielded about 50 candidates. A Ts phenotype was then verified in complex liquid media as failure of a culture to grow for a total of five generations following a shift from $70^{\circ} \mathrm{C}$ to $81^{\circ} \mathrm{C}$.

\section{Flow cytometry and microscopy analyses}

A typical DNA content distribution obtained by flow cytometry analysis of wild-type Sulfolobus cells growing exponentially at a constant temperature is depicted schematically in Fig. 1 (Bernander \& Poplawski, 1997). We screened the Ts mutants for deviations from this distribution, as well as for an altered cell-size distribution, after a shift from $70{ }^{\circ} \mathrm{C}$ to the non-permissive temperature $\left(81^{\circ} \mathrm{C}\right)$. First, we determined the effects of 
$70^{\circ} \mathrm{C}$, exponential growth

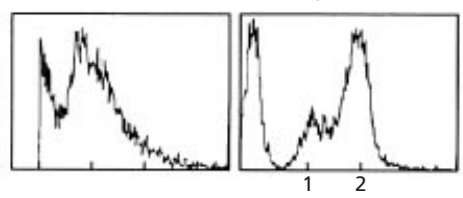

$81^{\circ} \mathrm{C}, 3 \mathrm{~h}$

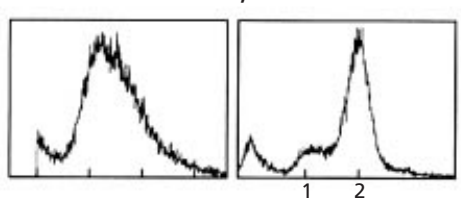

$81^{\circ} \mathrm{C}, 6 \mathrm{~h}$

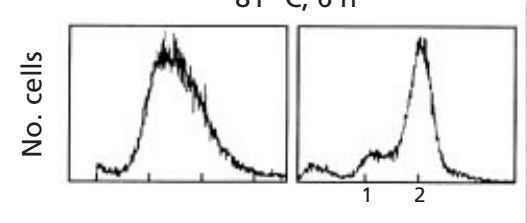

$81^{\circ} \mathrm{C}, 10 \mathrm{~h}$

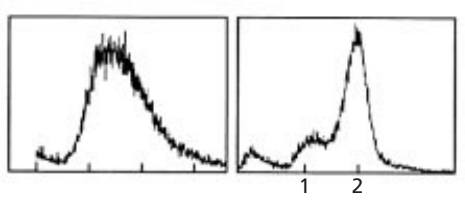

$81^{\circ} \mathrm{C}$, overnight $(>20 \mathrm{~h})$

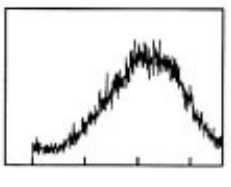

Cell size
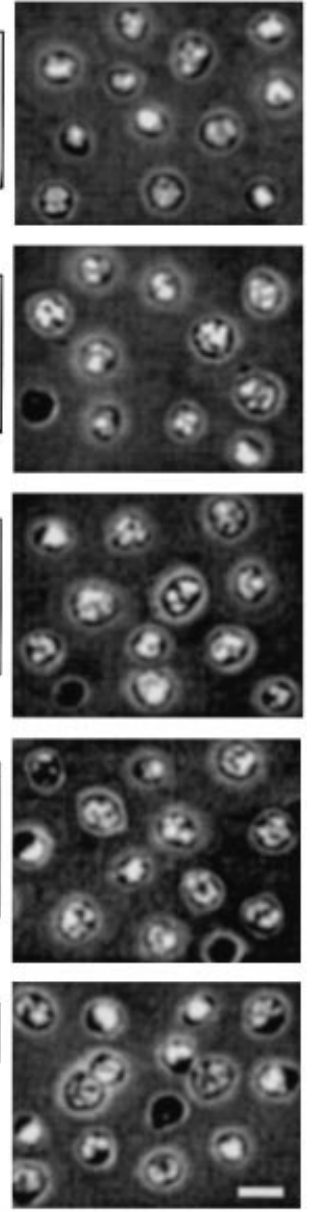

equivalents

Fig. 2. Flow cytometry distributions and phase-contrast/ fluorescence micrographs of the parent strain DG64 during a shift from $70^{\circ} \mathrm{C}$ to $81^{\circ} \mathrm{C}$. The cells were stained with the DNA-specific mithramycin A+ethidium bromide or DAPI dyes (see Methods) and analysed by flow cytometry and epifluorescence microscopy. The light scatter and fluorescence signals in the flow cytometry distributions are proportional to cellular mass and DNA content, respectively (see also Fig. 1). Cell sizes were obtained in relative units. Note that the leftmost part of each distribution corresponds to background noise (cell debris, 'dirt' particles etc.). The micrographs in the right column contain collections of cells that were selected one by one to illustrate different phenotypes, i.e. they do not represent random microscope fields.

this treatment on the parental strain, DG64, an auxotroph that relies on exogenous pyrimidines for nucleic acid synthesis. The post-replication stage dominated the cell cycle in DG64 cells grown at $70{ }^{\circ} \mathrm{C}$ (Fig. 2, top row), similar to wild-type $S$. acidocaldarius and Sulfolobus solfataricus strains grown at $80{ }^{\circ} \mathrm{C}$ (Bernander \& Poplawski, 1997; compare with Fig. 1). The shift to $81^{\circ} \mathrm{C}$ resulted in a slight increase in light scatter and in a somewhat reduced proportion of cells in the prereplication (B) and replication (C) periods (Fig. 2, second row), showing that the culture adapted to the changed growth conditions. The overnight sample (bottom row)

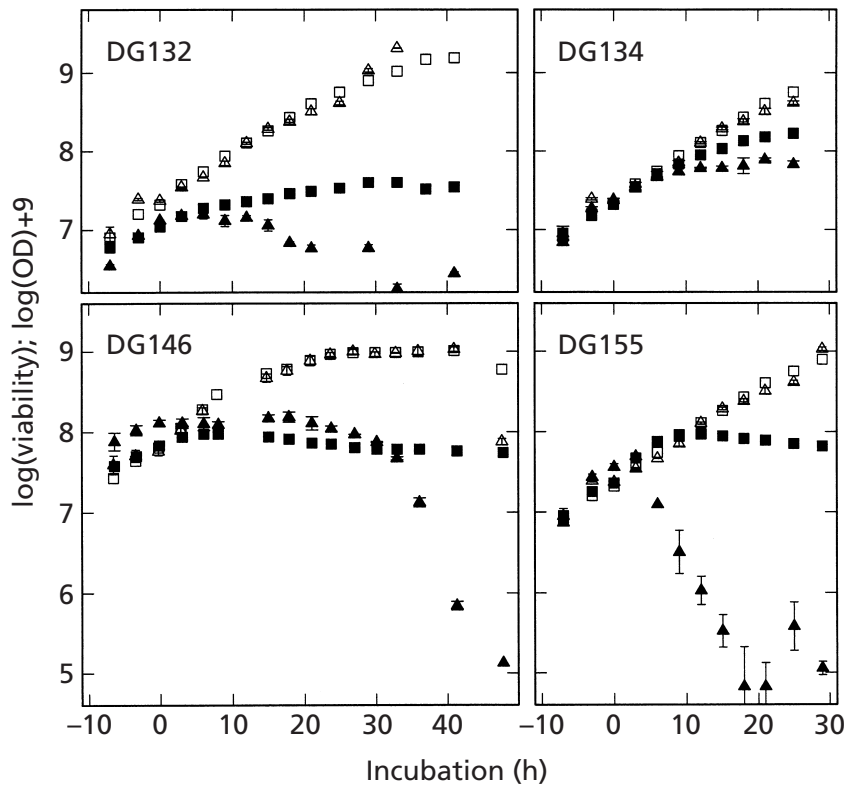

Fig. 3. Effects of temperature shift on growth and viability. Liquid exponential-phase cultures were shifted from $70^{\circ} \mathrm{C}$ to $81^{\circ} \mathrm{C}$ at time zero as described in Methods. The panels show the log of the apparent $O_{600}$ plus an arbitrary constant (9.0) to superimpose the turbidity (square symbols) and viability (triangular symbols) curves. For each Ts mutant, the results for the parental strain are included for comparison (white symbols). Viability data are means of duplicate culture samples; the ranges are indicated by error bars, which in most cases are obscured by the symbol. The time scales are different for DG132 and DG146 in order to show the late effects on the viability of these mutants.

had a higher proportion of cells with two fully replicated chromosomes, but had not yet fully entered stationary phase (Bernander \& Poplawski, 1997), as shown by persistence of the B- and C-period populations. A minor peak corresponding to cells with $>2$ chromosomes was also evident, and very few $(<1 \%)$ DNA-less cells were observed by microscopy. Turbidity and viability measurements showed that the growth kinetics remained exponential after the shift and that, under these conditions, the parental strain reached a high cell concentration $\left(>10^{9}\right.$ c.f.u. $\mathrm{ml}^{-1}$ ) and maintained viability for many hours after reaching stationary phase (Fig. 3).

A total of 34 mutants confirmed to be Ts were similarly analysed and then grouped into different classes based upon their response to the temperature shift (Table 1). For the representative mutants described below, the growth rate and efficiency of plating (Fig. 3), as well as the distributions of cell size and DNA content (first row in Figs 4-7), were close to normal at the permissive temperature.

\section{Cell-cycle arrest}

The mutants of classes Ia and Ib (Table 1) all arrested in the post-replication (D period; $G_{2}$ stage) part of the cell cycle at the non-permissive temperature, as indicated by 
Table 1. Phenotypic effects after shifting to the non-permissive temperature

Designations: + , phenotype present; -, phenotype absent; 3, 6, 10 and o/n indicate hours post-shift at which the phenotype first became evident. Parentheses indicate an intermediate phenotype.

\begin{tabular}{|c|c|c|c|c|c|c|}
\hline & \multicolumn{6}{|c|}{ Mutant class } \\
\hline & Ia & $\mathrm{Ib}$ & IIa & IIb & III & IV \\
\hline No. isolates & 4 & 5 & 5 & 3 & 4 & 3 \\
\hline Representative strain (DG number) & 132 & 146 & 149 & 155 & 134 & 117 \\
\hline \multicolumn{7}{|l|}{ Flow cytometry } \\
\hline Cell-cycle arrest in D period & 3 & 3 & - & - & - & - \\
\hline $\begin{array}{l}\text { Cells with }>2 \text { chromosome } \\
\text { equivalents }\end{array}$ & $(\mathrm{o} / \mathrm{n})$ & - & - & - & 6 & $(\mathrm{o} / \mathrm{n})$ \\
\hline Cell-size increase & + & - & - & $(+)$ & + & - \\
\hline DNA degradation & $\mathrm{o} / \mathrm{n}$ & $\mathrm{o} / \mathrm{n}$ & 10 & 6 & - & - \\
\hline \multicolumn{7}{|l|}{ Mass increase after shift (OD) } \\
\hline $\begin{array}{l}\text { Significant decrease compared to } \\
\text { WT }\end{array}$ & + & + & + & + & + & - \\
\hline Rapid growth arrest* & - & + & - & $(+)$ & - & - \\
\hline Reversion frequency & $1 \cdot 2 \times 10^{-7}$ & $5 \cdot 8 \times 10^{-7}$ & & $1.3 \times 10^{-7}$ & $8 \cdot 2 \times 10^{-6}$ & \\
\hline SD & $\begin{array}{c}1.4 \times 10^{-7} \\
\mathrm{n}=7\end{array}$ & $\begin{array}{l}5 \cdot 9 \times 10^{-7} \\
\mathrm{n}=5\end{array}$ & & $\begin{array}{c}8 \times 10^{-8} \\
\mathrm{n}=6\end{array}$ & $\begin{array}{l}1 \times 10^{-5} \\
\mathrm{n}=3\end{array}$ & \\
\hline
\end{tabular}

* OD increase corresponding to less than one mass doubling after the temperature shift to $81{ }^{\circ} \mathrm{C}$.

Parentheses indicate a mass increase corresponding to between one and two mass doublings.

the complete disappearance of the populations containing $<2$ chromosome equivalents in the DNA content distributions. Class Ia, represented by mutant DG132, showed a decreased growth rate and a slight drop in viability after the shift to $81^{\circ} \mathrm{C}$ (Fig. 3). In agreement with the turbidity measurements, flow cytometry revealed that the light scatter signals increased significantly in strength throughout the experiment (Fig. 4 , first column). Thus, cell division was blocked and a clear continuous cell-size increase occurred over time. In the flow cytometry analysis, all DG132 cells already contained two chromosomes at the $3 \mathrm{~h}$ time point (Fig. 4 , second row). This indicated that replication had continued to termination at the non-permissive temperature and that no new rounds had been initiated, such that all cells ended up with two fully replicated chromosomes. That division was blocked was further supported by the observation that no cells with only a single chromosome appeared at the 3, 6 and $10 \mathrm{~h}$ time points. Growth without concomitant cell division was also apparent in the microscopy analysis as a dramatic increase in cell size over time (Fig. 4, right column).

After overnight incubation at $81^{\circ} \mathrm{C}$, most cells exhibited a dramatic reorganization of the nucleoid; the intracellular regions of fluorescence became unstructured and accumulated in a 'half-moon' appearance (Fig. 4, bottom micrograph). In part of the population, the DNA had become degraded (Fig. 4, cells with $<1$ chromosome equivalent in bottom two rows), although the cells still were intact in the microscopy analysis. In plots correlating cell size and DNA content (not shown), the DNA-less cells formed a distinct population displaying a decreased light scatter.

Mutants of class Ib similarly accumulated in the postreplication period, but with little or no cell-size increase after the shift, as represented by strain DG146. Flow cytometry (Fig. 5) showed that the DG146 cells had arrested in the $\mathrm{D}$ period by the $3 \mathrm{~h}$ time point, whereas the light-scatter distribution remained largely unaffected, indicating that chromosome replication had continued to completion while cellular growth stopped. Prolonged incubation at $81^{\circ} \mathrm{C}(>30 \mathrm{~h})$ resulted in eventual loss of cell integrity, as shown by decreased light scatter and production of cell ghosts with grainy interiors (Fig. 5). Furthermore, massive DNA degradation occurred, such that at $48 \mathrm{~h}$ the frequency of cells containing $\geqslant 1$ chromosome equivalent had decreased to about $1 \times 10^{-3}$ (Fig. 5, bottom row). Consequently, the viability dropped dramatically at late time points (Fig. 3).

\section{Growth decrease without cell-cycle arrest}

Two classes of mutants (IIa and IIb) showed decreased growth after the temperature shift, but no obvious cellcycle arrest. Mutants of class IIa showed a gradual decrease in growth rate over a $20 \mathrm{~h}$ period. In the flow cytometry analysis, the only significant effects detected 
$70^{\circ} \mathrm{C}$, exponential growth

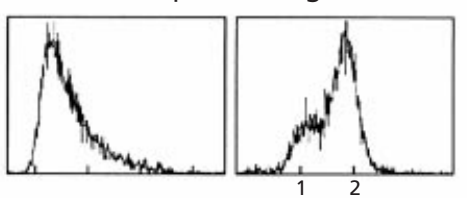

$81^{\circ} \mathrm{C}, 3 \mathrm{~h}$

$81^{\circ} \mathrm{C}, 6 \mathrm{~h}$

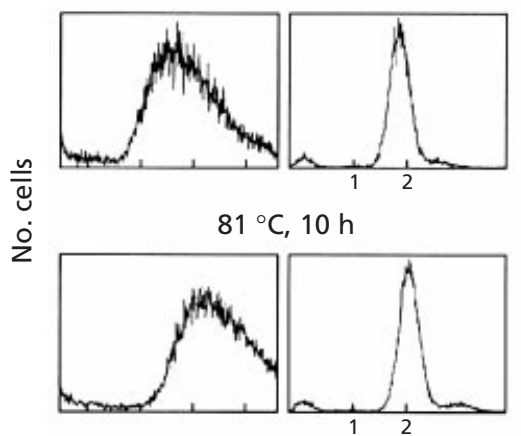

$81^{\circ} \mathrm{C}$, overnight $(>20 \mathrm{~h})$

Reduced amplification

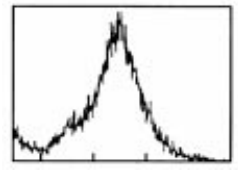

Cell size
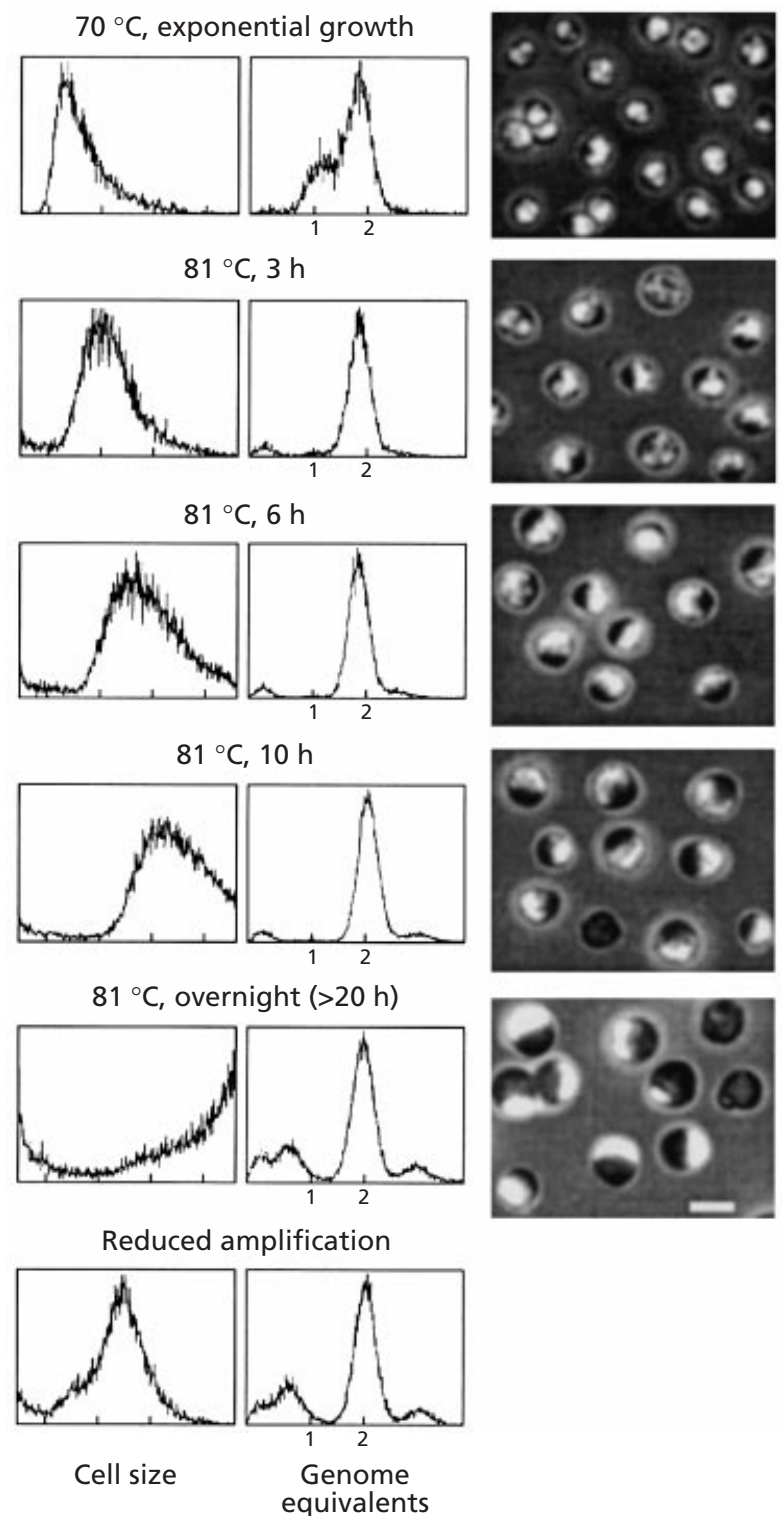

Fig. 4. Flow cytometry and microscopy of strain DG132 (phenotypic class la) during a shift to the non-permissive temperature. See Fig. 2 for details. In the bottom row, the instrument amplification was reduced for the light-scatter (cell size) parameter to display the full range of values obtained.

were DNA degradation in two of the mutants. This class is therefore not exemplified in the figures.

Class IIb exhibited a more rapid halt in growth and is represented by strain DG155. Both the turbidity and the viability counts continued to increase for about two doublings after the temperature shift (Fig. 3). During this early interval, flow cytometry revealed that chromosome replication and cell division continued, although the replicating part of the population decreased in proportion, while no major effects on cell morphology or nucleoid structure were detected in the microscopy
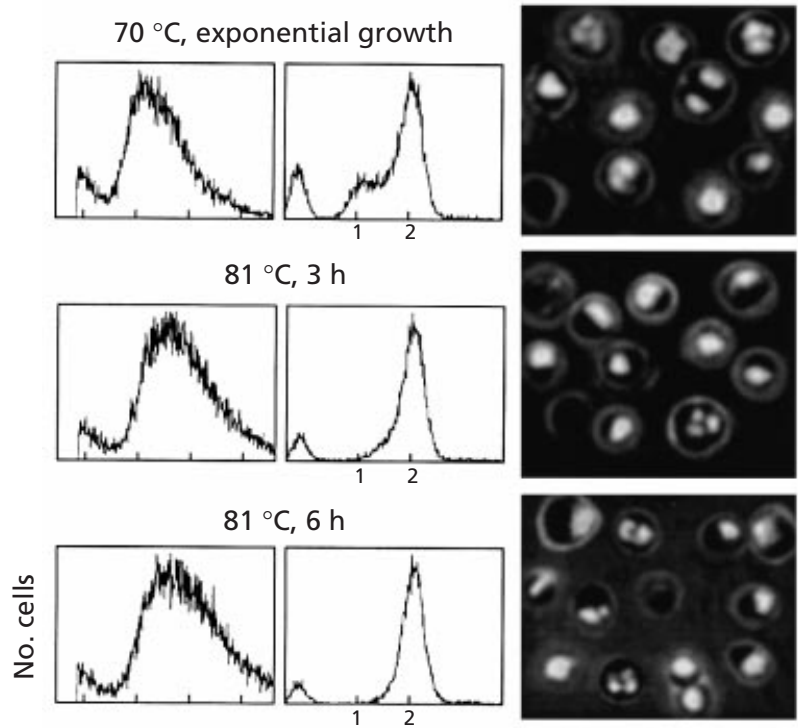

$81^{\circ} \mathrm{C}, 33 \mathrm{~h}$
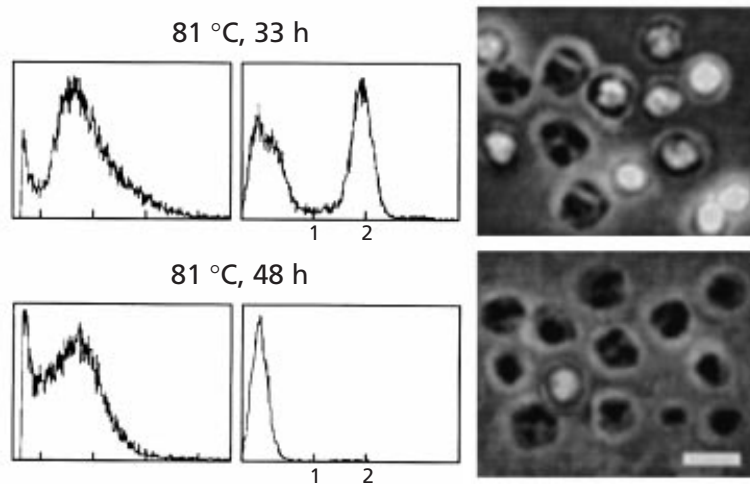

Cell size

equivalents

Fig. 5. Flow cytometry and microscopy of strain DG146 (phenotypic class Ib) during a shift to the non-permissive temperature. Note that the sampling times are different from those in Figs 2, 4, 6 and 7 since the effects on viability of the temperature shift occurred later for DG146. See Fig. 2 for details.

analysis (Fig. 6). However, at later time points viability fell dramatically (Fig. 3), accompanied by loss of DNA and decreased light-scattering signals (Fig. 6). This early timing of culture death contrasted with the delayed effects observed for DG146 (above).

\section{DNA increase}

Class III mutants showed continued increase in cellular DNA content after the temperature shift, accompanied by slow but persistent growth. The most dramatic example of this phenotype was exhibited by strain DG134. After temperature shift, total cell mass continued to increase, whereas the increase in c.f.u. soon halted, resulting in a divergence of the turbidity and viability curves (Fig. 3). Flow cytometry and microscopy indicated that this divergence could not be attributed to 
$70^{\circ} \mathrm{C}$, exponential growth

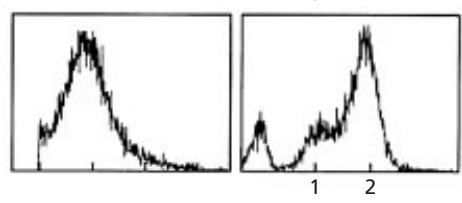

$81{ }^{\circ} \mathrm{C}, 3 \mathrm{~h}$

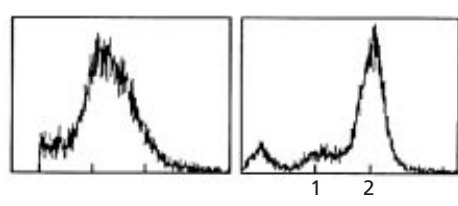

$81^{\circ} \mathrm{C}, 6 \mathrm{~h}$

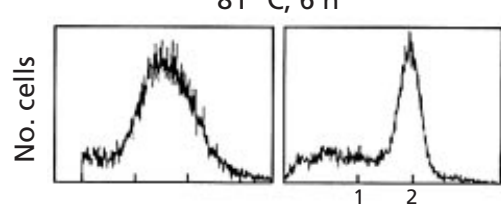

$81{ }^{\circ} \mathrm{C}, 10 \mathrm{~h}$

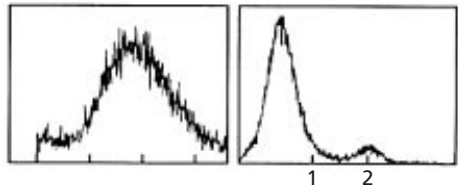

$81^{\circ} \mathrm{C}$, overnight $(>20 \mathrm{~h})$

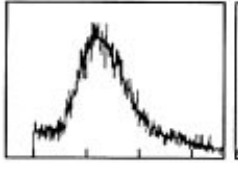

Cell size
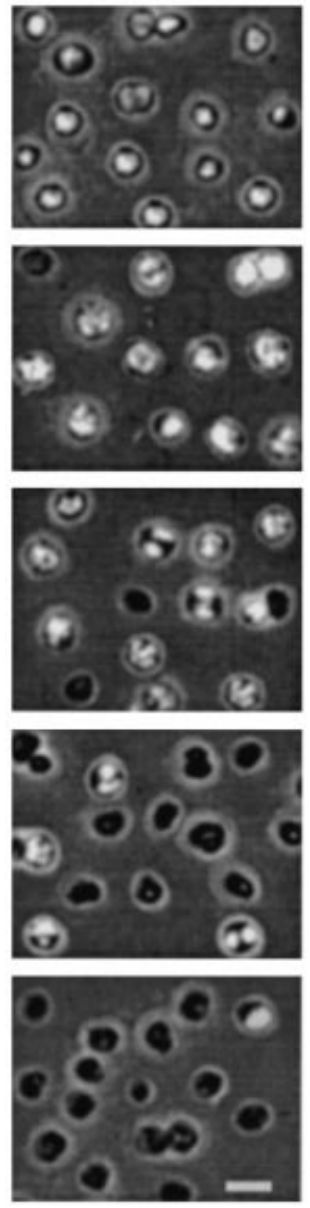

Fig. 6. Flow cytometry and microscopy of strain DG155 (phenotypic class IIb) during a shift to the non-permissive temperature. See Fig. 2 for details.

an accumulation of dead cells, as was seen in several of the other Ts mutants examined. Instead, the divergence reflected continued growth in the absence of cell division, indicating that division was inhibited (Fig. 7, first column). The large broadening of the distribution implied that cell growth ceased at different time points in different parts of the cell population.

Although we also observed cell enlargement in other cases (see above), strain DG134 had the distinguishing characteristic that the DNA content of the cells also increased with time. Thus, replication did not cease after the temperature shift, although the replicating part of the population decreased in proportion (Fig. 7, second column). Replication was further evident as a rightward broadening of the two-chromosome peak in the DNA content distributions, and the eventual appearance of peaks corresponding to 3,4 and even 5 chromosome equivalents per cell (Fig. 7, bottom row). Microscopy analysis (Fig. 7, right column) confirmed the flow cytometry results: an obvious cell-size increase over
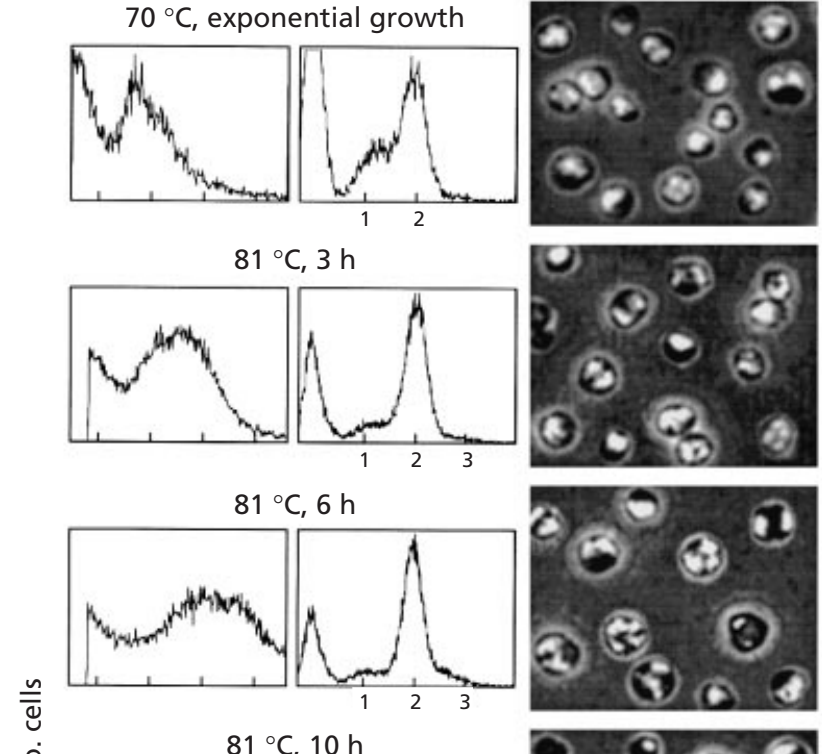

i
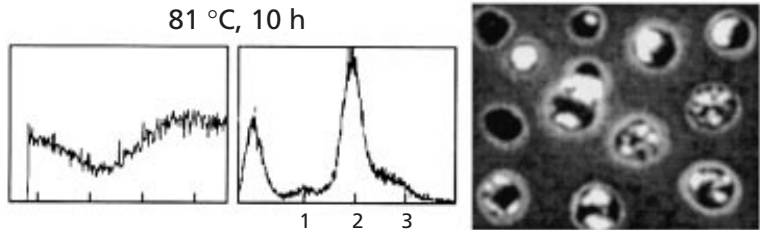

$81^{\circ} \mathrm{C}$, overnight $(>20 \mathrm{~h})$
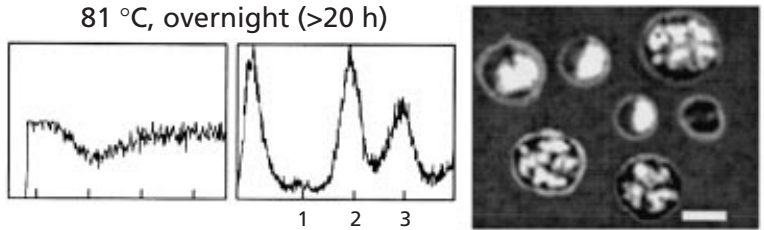

Reduced amplification

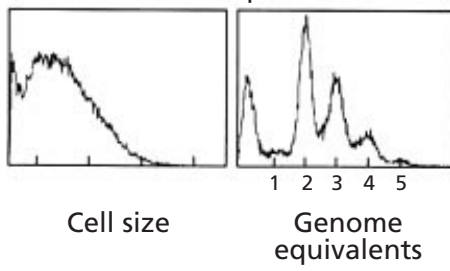

Fig. 7. Flow cytometry and microscopy of strain DG134 (phenotypic class III) during a shift to the non-permissive temperature. See Fig. 2 for details. In the bottom row, the instrument amplification was reduced for both the light-scatter and fluorescence parameters to display the full ranges of values obtained.

time was evident and giant multinucleated cells were present in the overnight sample. The DNA appeared as distinct and highly structured foci, which is the appearance of nucleoids in exponential-phase Sulfolobus cells. Interestingly, these nucleoids were obviously separated in some cells. This indicated that the partition (mitotic) apparatus was intact and active at the nonpermissive temperature, distributing the replicated chromosomes in different directions within the giant cells. The fact that overall viability (assayed at $70{ }^{\circ} \mathrm{C}$ ) did not decline over this time period suggests that the giant cells with highly structured and separated nucleoids remained 
intact and capable of resuming cell division at the permissive temperature.

\section{Other classes}

Several mutants did not show a major growth decrease during the shift experiments, but effects were still detectable in the flow-cytometry distributions; these were designated class IV (Table 1). In cultures of mutant DG117, for example, part of the cell population contained $>2$ chromosome equivalents at the overnight time point. The largest class of mutants, designated class $\mathrm{V}$, showed no obvious short-term effects of a temperature shift. The fact that these mutants were clearly Ts for prolonged growth in both solid and liquid media indicates that several generation times were required before the phenotypic consequences of the mutations significantly affected cell growth and survival. Classes IV and V are not depicted in the figures.

\section{DISCUSSION}

This is the first description of conditional-lethal mutants of an archaeon or of a hyperthermophile. At the permissive temperature, Ts mutants of $S$. acidocaldarius exhibited efficiencies of plating, cell sizes, cell morphology, DNA contents and nucleoid shapes closely resembling those of the parental strain. Furthermore, the non-permissive temperature used in our experiments is near the optimal growth temperature of wild-type $S$. acidocaldarius strains (about $80^{\circ} \mathrm{C}$; Grogan 1989). Together, this indicates acquisition of a conditional defect in at least one essential cellular function in each isolate. The observed phenotypic variety among the 34 Ts mutants suggests that a series of different genes and pathways are affected. This is consistent with the frequency of Ts mutants among the mutagenized cells, which was comparable to the frequency of $S$. acidocaldarius auxotrophs recovered by a similar isolation method (Grogan \& Gunsalus, 1993). The phenotypic reversion frequencies are consistent with the assumption that the $S$. acidocaldarius clones typically contain only a single new mutation each.

\section{Significant phenotypes}

Our previous qualitative and quantitative analyses of the cell cycle and cytology of different Sulfolobus species (Bernander, 1998; Bernander \& Poplawski, 1997; Hjort \& Bernander, 1999; Poplawski \& Bernander, 1997) provide a basis for interpreting several of the mutant phenotypes. In particular, the following responses were considered to be significant: i) cell-cycle arrest, ii) growth arrest or, alternatively, increasing cellular size over time, iii) increases in the number of chromosomes per cell and iv) changes in nucleoid organization. These phenotypes demonstrate that chromosome replication, cell division, nucleoid structure and distribution, and cellular growth, all of which are normally tightly controlled and co-ordinated, can be selectively inhibited or uncoupled in $S$. acidocaldarius.

\section{Post-replication arrest}

At the non-permissive temperature, mutants of classes Ia and $\mathrm{Ib}$ rapidly accumulated in the post-replication $\left(D / G_{2}\right.$; see Fig. 1) stage of the cell cycle. This indicates that ongoing rounds of chromosome replication were completed whereas subsequent cell division, as well as initiation of new rounds of replication, were blocked. This cell-cycle arrest was observed in a relatively large proportion of the mutants studied, including mutants that continued to grow after the temperature upshift, as well as those that stopped growing soon thereafter (Table 1$)$. Temporary arrest in $\mathrm{D}\left(\mathrm{G}_{2}\right)$ is observed when exponentially growing Sulfolobus cultures are diluted into fresh medium (Hjort \& Bernander, 1999), and cultures that reach stationary phase also arrest in $\mathrm{D}$ (Bernander \& Poplawski, 1997). Taken together, these observations suggest that the post-replication stage is a preferred cell-cycle-arrest stage in $S$. acidocaldarius, and that initiation of a new round of chromosome replication is prone to regulatory inhibition and particularly sensitive to cellular status.

In several mutants, including DG132 (Fig. 4) and DG134 (Fig. 7), incubation at the non-permissive temperature supported cellular growth without concomitant cell division, producing grossly enlarged cells. These mutants provide the first examples in an archaeon of genetic uncoupling of mass increase from cell division. They further demonstrate that initiation of cell division is also prone to inhibition and constitutes another important regulatory step in the $S$. acidocaldarius cell cycle. The fact that these and other Ts mutants stayed viable for several hours after arrest suggests that they may be used for cell-cycle synchronization of $S$. acidocaldarius cultures, in addition to the recently described synchronization method based upon dilution of stationary-phase cultures (Hjort \& Bernander, 1999).

\section{Division inhibition}

The phenotype of DG134 (continued growth and chromosome replication without cell division) is particulary noteworthy, as it suggests a block in the division process itself. In Sulfolobus, this phenotype is analogous to that of $f t s$ (filamentation temperature sensitive) mutants of E. coli (Hirota et al., 1968), upon which much of the genetic analysis of bacterial cell division has been based. Particular attention has been focussed on the fts $Z$ gene, whose product initiates bacterial cell division and participates in the constriction process (Lutkenhaus \& Addinall, 1997). Homologues of $f t s Z$ are found in all bacteria, except Chlamydia species, as well as in all archaea within the Euryarchaeota branch that have been analysed (Baumann \& Jackson, 1996; Bult et al., 1996; Kawarabayasi et al., 1998; Klenk et al., 1997; Margolin et al., 1996; Smith et al., 1997; Wang \& Lutkenhaus, 1996). However, no fts Z gene has yet been identified in a crenarchaeote, despite the availability of the complete genome sequence of Aeropyrum pernix (Kawarabayasi et al., 1999). The crenarchaeotal celldivision apparatus is therefore likely to be quite di- 
vergent from that of other prokaryotes, which focusses particular interest on the defect in strain DG134.

\section{Growth inhibition}

The majority of the mutants continued to grow after the temperature shift, suggesting that most cellular functions were unaffected at the non-permissive temperature. However, some mutants ceased growth rapidly, indicating that central cellular processes, e.g. protein synthesis, energy production or important biosynthetic pathways were affected. Our identification of several such mutants in a relatively small collection is consistent with the complexity of these processes and the large number of genes involved. The DNA degradation observed in several mutants, e.g. DG146 and DG155, may be a consequence of cell death and the concomitant acidification of the cytoplasm. This is supported by observations that other stresses, i.e. addition of non-ionic detergent (S. L. Strini \& D. W. Grogan, unpublished observations) or transiently shifting cultures to a low temperature (Hjort \& Bernander, 1999) also result in degradation of DNA in Sulfolobus cells.

\section{Changes in nucleoid structure}

In several of the mutants, the characteristic organization of the nucleoids in exponential phase (Poplawski \& Bernander, 1997) was lost after several hours incubation at the non-permissive temperature. The fluorescence foci became more diffuse and the nucleoids often accumulated in a 'half-moon' appearance near the cell periphery (exemplified by mutant DG132). Although the mechanistic basis for these structural changes remains to be investigated, we note that they may be associated with general loss of cellular function and integrity, as they were often accompanied by onset of DNA degradation in other cells of the same culture.

\section{Nucleoid segregation and chromosome replication}

Strain DG134 maintained cell viability for a long time after the shift to the non-permissive temperature, accompanied by retained exponential-phase nucleoid structure and continued chromosome replication. Individual nucleoids could be distinguished even when as many as five were present within a single cell (Fig. 7). This showed that active segregation of replicated genomes continued to take place, i.e. that the partition (mitotic) machinery continued to operate at the nonpermissive temperature. In contrast, mutant DG132 showed little nucleoid segregation at the non-permissive temperature, and the level of chromosome re-replication was no higher than in the DG64 parental strain (compare overnight samples in Figs 2 and 4). Tight coupling between nucleoid partition, cell division and chromosome replication is observed in wild-type strains: when a stationary phase culture, in which all cells are in the post-replication stage of the cell cycle, is diluted into fresh medium, initiation of replication does not occur until the preceding nucleoid partition and cell division events have been completed (Hjort \& Bernander, 1999). However, the results obtained with strains DG132 and DG134 suggest that only chromosome partition is required before a new round of replication can be initiated, whereas cell division is not essential. Thus, alternating rounds of replication and chromosome segregation is a key regulatory feature of the crenarchaeal cell cycle.

\section{ACKNOWLEDGEMENTS}

D. W. G. acknowledges the technical assistance of E. Medigholi in the isolation of mutants and of S. Lippert and S. Hughes in growth measurements. This work was supported by the Swedish Natural Science Research Council, the Swedish Foundation for Strategic Research and the U.S. Office of Naval Research grant N-00014-94-I-0393.

\section{REFERENCES}

Baumann, P. \& Jackson, S. P. (1996). An archaebacterial homologue of the essential eubacterial cell division protein FtsZ. Proc Natl Acad Sci USA 93, 6726-6730.

Bernander, R. (1998). Archaea and the cell cycle. Mol Microbiol 29, 955-961.

Bernander, R. \& Poplawski, A. (1997). Cell cycle characteristics of thermophilic archaea. J Bacteriol 179, 4963-4969.

Bult, C. J., White, O., Olsen, G. J. \& 37 other authors (1996). Complete genome sequence of the methanogenic archaeon, Methanococcus jannaschii. Science 273, 1058-1073.

Grogan, D. W. (1989). Phenotypic characterization of the archaebacterial genus Sulfolobus: comparison of five wild-type strains. J Bacteriol 171, 6710-6719.

Grogan, D. W. (1995). Isolation of Sulfolobus acidocaldarius mutants. In Archaea: a Laboratory Manual: Thermophiles, pp. 125-131. Edited by F. T. Robb and others. Cold Spring Harbor, NY : Cold Spring Harbor Laboratory.

Grogan, D. W. (1996). Exchange of genetic markers at extremely high temperatures in the archaeon Sulfolobus acidocaldarius. J Bacteriol 178, 3207-3211.

Grogan, D. W. \& Gunsalus, R. P. (1993). Sulfolobus acidocaldarius synthesizes UMP via a standard de novo pathway: results of a biochemical-genetic study. J Bacteriol 175, 1500-1507.

Hirota, Y., Ryter, A. \& Jacob, F. (1968). Thermosensitive mutants of $E$. coli affected in the processes of DNA synthesis and cellular division. Cold Spring Harbor Symp Quant Biol 33, 677-694.

Hjort, K. \& Bernander, R. (1999). Changes in cell size and DNA content in Sulfolobus cultures during dilution and temperature shift experiments. J Bacteriol 181, 5669-5675.

Kawarabayasi, Y., Sawada, M., Horikawa, H. \& 28 other authors (1998). Complete sequence and gene organization of the genome of a hyperthermophilic archaebacterium, Pyrococcus horikoshii OT3. DNA Res 5, 55-76.

Kawarabayasi, Y., Hino, Y., Horikawa, H. \& 27 other authors (1999). Complete genome sequence of an aerobic hyperthermophilic crenarchaeon, Aeropyrum pernix K1. DNA Res 6, 83-101.

Klenk, H.-P., Clayton, R. A., Tomb, J.-F. \& 48 other authors (1997). The complete genome sequence of the hyperthermophilic, sulphate-reducing archaeon Archaeoglobus fulgidus. Nature 390, 364-370. 
Lutkenhaus, J. \& Addinall, S. G. (1997). Bacterial cell division and the $\mathrm{Z}$ ring. Ann Rev Biochem 66, 93-116.

Margolin, W., Wang, R. \& Kumar, M. (1996). Isolation of an fts $Z$ homolog from the Archaebacterium Halobacterium salinarium: implications for the evolution of FtsZ and tubulin. J Bacteriol 178, 1320-1327.

Poplawski, A. \& Bernander, R. (1997). Nucleoid structure and distribution in thermophilic archaea. J Bacteriol 179, 7625-7630.

Schleper, C., Röder, R., Singer, T. \& Zillig, W. (1994). An insertion element of the extremely thermophilic archaeon Sulfolobus solfataricus transposes into the endogenous $\beta$-galactosidase gene. Mol Gen Genet 243, 91-96.

Smith, D. R., Doucette-Stamm, L. A., Deloughery, C. \& 34 other authors (1997). Complete genome sequence of Methano- bacterium thermoautotrophicum $\Delta \mathrm{H}$ : functional analysis and comparative genomics. J Bacteriol 179, 7135-7155.

Stetter, K. O. (1999). Extremophiles and their adaptation to hot environments. FEBS Lett 452, 22-25.

Wang, X. \& Lutkenhaus, J. (1996). FtsZ ring: the eubacterial division apparatus conserved in archaebacteria. Mol Microbiol 21, 313-319.

Woese, C. R., Kandler, O. \& Wheelis, M. L. (1990). Towards a natural system of organisms: proposal for the domains Archaea, Bacteria, and Eucarya. Proc Natl Acad Sci USA 87, 4576-4579.

Received 12 August 1999; revised 17 November 1999; accepted 24 November 1999. 